\title{
Congratulations Hartmut Brückmann!
}

\author{
Jennifer Linn • Gernot Schulte-Altedorneburg • \\ Martin Wiesmann
}

Published online: 2 April 2011

(C) Springer-Verlag 2011

On 09 April 2011 Prof. Dr. med. Hartmut Brückmann head of the Department of Neuroradiology of the University Clinic Munich will become 60 years old. At the same time his department at the Großhadern Clinic will have been in existence for 15 years.

Hartmut Brückmann was born in Freinsheim in Rhineland and grew up in Kevelaer on the Lower Rhine. After completing school he studied medicine and ethnology in Aachen and Bonn. He had already become interested in radiology during his doctoral studies and deepened this interest during his further education in radiology at the Knappschaftskrankenhaus Bardenberg under Prof. Medini Cen. Subsequently, in 1985 Hartmut Brückmann moved to the Neurological University Clinic Aachen (Prof. Dr. K. Poeck) which was already taking a pioneering role in the diagnostics and treatment of stroke. During this time he was inspired by Hermann Zeumer, later to become professor of neuroradiology at the University Clinic Hamburg-Eppendorf in diagnostic and especially interventional neuroradiology. Together they carried out endovascular recanalizing interventions in the vertebrobasilar vascular territory as early as the 1980s. With the establishment of a teaching and research department of neuroradiology at the University Clinic Aachen, Hartmut Brückmann became Vice Medical Director under his former boss, Prof. Armin Thron in 1987. In 1990 he moved to the Medical University of Lübeck, where he completed his postdoctoral studies in 1993. In his postdoctoral thesis "Classification of infarcts of the pons and of the medulla oblongata" he investigated the vascularization of the brain

J. Linn $(\bowtie) \cdot$ G. Schulte-Altedorneburg

Munich, Germany

e-mail: linn@nrad.de

M. Wiesmann

Aachen, Germany

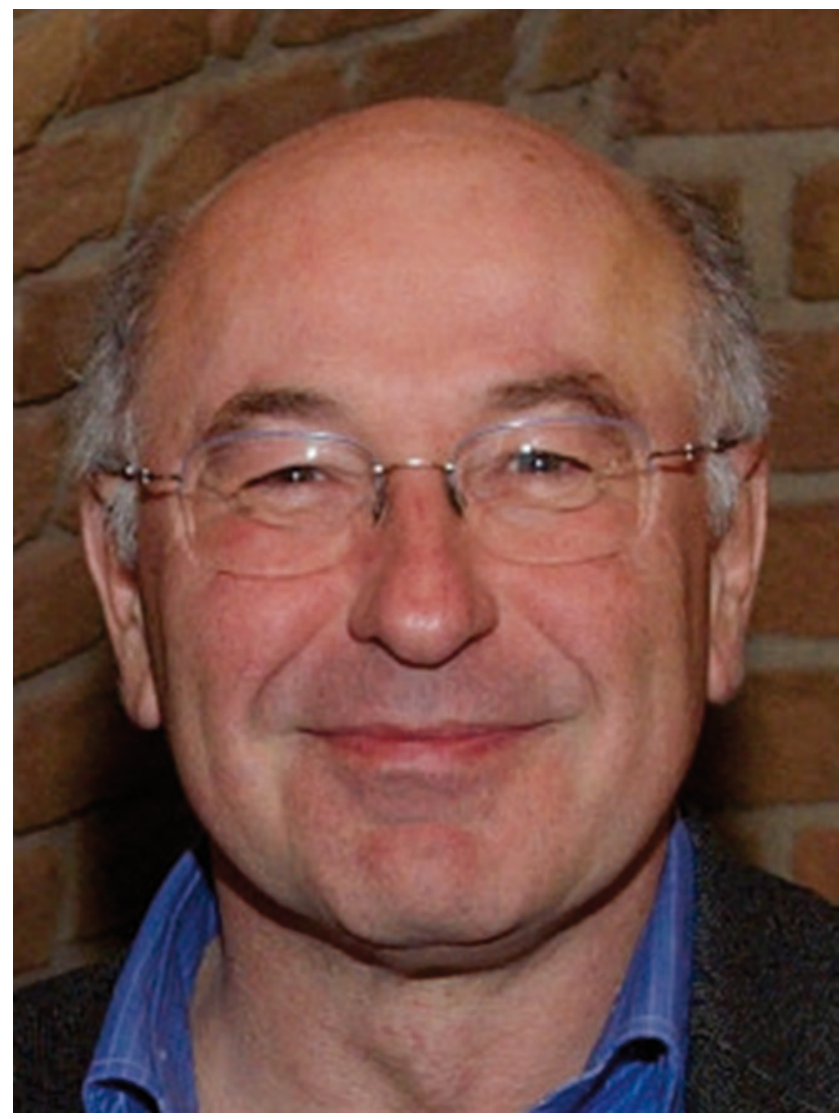

stem on the basis of microradiographical preparations. Since 01 April 1996 H. Brückmann is head of the Department for Neuroradiology at the Ludwig-Maximilans-University Munich-Großhadern as a university professor.

Hartmut Brückmann's scientific and clinical focal points are neurovascular diseases, particularly ischemic infarctions in the vertebrobasilar vascular territory. His pioneering 
work in intra-arterial thrombolysis of the basilar artery and in angioplasty of the vertebral artery, which he began with his teacher and mentor H. Zeumer in Aachen, should be highlighted. In addition, in Lübeck and Munich, he took the technique and diagnostic evaluation of mechanical recanalization of the intracranial arteries considerably further together with Thomas Mayer, now professor in neuroradiology at the University of Jena. At the forefront of his scientific work always stood and still stands the clinical relevance of a hypothesis, which can also be seen in doctoral theses supervised by him. In scientific presentations and also in student lectures he understands how to capture and enthuse his audience, especially with exciting case histories from his rich clinical experience.

In the everyday routine of the clinic Hartmut Brückmann also places great emphasis on encouraging his staff to take a symptom and illness-oriented approach. What is essential to him is dealing with patients and their relatives with empathy. Thus, he takes a lot of time during his daily visits to patients undergoing neuroradiological treatment and expects the same approach from his staff, too.

Hartmut Brückmann encourages the independence of his staff by always showing openness to new ideas and projects and sustainably supporting their implementation. In doing so he is always concerned to develop his staff both professionally and personally. The personal wishes of his staff are just as important to him as their direct professional tasks and targets. His sees his responsibility in terms of good management as not restricted to working times and the workplace but also commits himself for his staff beyond this out of conviction and loyalty.

One of Hartmut Brückmann's other great strengths is reminding young, ambitious staff members striving for scientific merits of their actual, namely their medical activities, in a friendly manner. His maxim, which is as simple as it is fundamental, to make clear the suitable priorities for medical employment is: "What is decisive is the patient, whose suffering we must recognize and treat sufficiently."

Because Hartmut Brückmann understands neuroradiology not only as a profession but also as a vocation in the literal sense, the maintenance and further development of the speciality is close to his heart. This is reflected in his many years of intensive commitment to professional policy: Hartmut Brückmann is a member of the Board of the German Society of Neuroradiology (DGNR) since many years and he was President of the DGNR from 2006 to 2008. His activities as a member of the Board and as President were and still are focussed on consolidating the discipline neuroradiology in cooperation with other neuro-specialities. With great interpersonal skills and unpretentious advocacy, he has won the respect and understanding of his colleagues in the related disciplines. Thus, during his presidency, in establishing a joint office of the DGNR and the German Society of Radiology, H. Brückmann succeeded in creating a sustainable mark of interdisciplinary cooperation.

As his pupils and friends it is of particular importance to us and a great pleasure to congratulate Hartmut Brückmann most sincerely on his 60th birthday. At the same time we would like to thank him for the stimulating manner with which he passes on his great diagnostic and interventional neuroradiological knowledge to us. Hartmut Brückmann is a model role to us in many things. We are also pleased to take this opportunity to express our gratitude to him for his extraordinary personal and friendly support in professional and in private affairs. 